\title{
Randomized Controlled Trial Comparing Different Single Doses of Intravenous Paracetamol for Placement of Peripherally Inserted Central Catheters in Preterm Infants
}

\author{
Daniella W.E. Roofthooft ${ }^{a}$ Sinno H.P. Simons ${ }^{a}$ Richard A. van Lingen ${ }^{c}$ \\ Dick Tibboel $^{b}$ John N. van den Ankerb, d, e Irwin K.H. Reiss ${ }^{a}$ \\ Monique van Dijk ${ }^{\mathrm{a}, \mathrm{b}}$
}

a Division of Neonatology, Department of Pediatrics, and ${ }^{\mathrm{b}}$ Intensive Care and Department of Pediatric Surgery, Erasmus MC-Sophia Children's Hospital, Rotterdam, and 'Division of Neonatology, Princess Amalia Department of Pediatrics, Isala Clinics, Zwolle, The Netherlands; ${ }^{d}$ Division of Pediatric Clinical Pharmacology, Children's National Medical Center, Washington, DC, USA; ${ }^{~}$ Division of Pediatric Pharmacology and Pharmacometrics, University Children's Hospital, Basel, Switzerland

\section{Keywords}

Procedural pain - Analgesia - Paracetamol - Central line ·

Premature Infant Pain Profile · Preterm infants

\begin{abstract}
Background: The availability of a safe and effective pharmacological therapy to reduce procedural pain in preterm infants is limited. The effective analgesic single dose of intravenous paracetamol in preterm infants is unknown. Comparative studies on efficacy of different paracetamol doses in preterm infants are lacking. Objectives: To determine the analgesic effects of different single intravenous paracetamol doses on pain from peripherally inserted central catheter (PICC) placement in preterm infants. Methods: In a blinded randomized controlled trial, the analgesic effects of 10-, 15-, and $20-\mathrm{mg} / \mathrm{kg}$ single-dose intravenous paracetamol before PICC placement were compared in neonates with a gestational age <32 weeks. Secondly, a separate age-matched nonrandomized control group receiving oral sucrose was
\end{abstract}

\section{KARGER}

E-Mail karger@karger.com www.karger.com/neo
This article is licensed under the Creative Commons AttributionNonCommercial-NoDerivatives 4.0 International License (CC BYNC-ND) (http://www.karger.com/Services/OpenAccessLicense).
Usage and distribution for commercial purposes as well as any distribution of modified material requires written permission. included. Pain was assessed with the Premature Infant Pain Profile (PIPP) and the COMFORTneo score. Peak plasma concentrations of paracetamol were determined. Results: A total of 60 patients were included in the paracetamol dose groups (median gestational age $=27.8$, IQR: 25.7-29.2 weeks). PIPP scores were comparable: median $=8$ (IQR: 6-10.5), 7 (IQR: 6-9), and 8 (IQR: 6-10) for the 10-, 15-, and $20-\mathrm{mg} / \mathrm{kg}$ paracetamol groups, respectively ( $p=0.94$ ). COMFORTneo scores were not statistically different between the different paracetamol dose groups ( $p=0.35$ ). All randomized subjects, except for 3 who received $10 \mathrm{mg} /$ $\mathrm{kg}$ of paracetamol, had peak paracetamol concentrations $>9 \mathrm{mg} / \mathrm{L}$. PIPP $(p=0.78)$ and COMFORTneo $(p=0.08)$ scores were also comparable between paracetamol- and sucrosetreated patients. Conclusions: We found no analgesic benefit from intravenous paracetamol studied in different single doses over sucrose for PICC placement in preterm infants. Paracetamol is not a suitable analgesic for this procedure in preterm infants.

(c) 2017 The Author(s) Published by S. Karger AG, Basel
Daniella W.E. Roofthooft, MD, PhD

Erasmus MC-Sophia Children's Hospital

Department of Pediatrics, Division of Neonatology

Wytemaweg 80, NL-3015 CN Rotterdam (The Netherlands)

E-Mail d.roofthooft@erasmusmc.nl 


\section{Introduction}

Today, pain assessment is an essential component of medical care for preterm infants who undergo many painful procedures $[1,2]$. Analgesia is necessary to protect against the negative short- and long-term consequences of pain from skin-breaking procedures such as changes in brain development [3]. The analgesic properties of sucrose to reduce procedural pain have been questioned although its administration is the standard of care in many NICUs [4]. Long-acting opioids, such as morphine, do not effectively reduce pain from heel sticks in preterm infants [5]. The reluctance to use strong analgesic drugs in newborns is triggered by studies in rodents showing accelerated neuronal apoptosis [6]. Such findings warrant studies on the effectiveness and safety of other analgesics, such as paracetamol.

Paracetamol is the most used drug to relieve mild to moderate pain in children and adults. Its safety and efficacy after intravenous administration have not yet been proven in preterm infants.

The objective of this study was to determine the analgesic effect of 3 different single doses of paracetamol before peripherally inserted central catheter (PICC) placement in preterm infants in a randomized controlled trial. Additionally, a nonrandomized age-matched sucrose control group was added.

\section{Methods}

\section{Design, Patients, and Setting}

This multicenter, blinded, randomized controlled trial was performed from October 2010 until October 2013 at the level III NICUs of the Erasmus MC-Sophia Children's Hospital in Rotterdam and the Isala Clinics in Zwolle, the Netherlands. Recruitment of eligible patients was strictly performed by members of the research team. Subjects were randomly allocated to 10-, 15-, or 20$\mathrm{mg} / \mathrm{kg}$ single-dose paracetamol (Perfalgan $^{{ }^{\odot}}$; Bristol-Meyers Squibb) given before PICC placement.

Inclusion criteria were gestational age $<32$ weeks, an indwelling arterial catheter, and PICC placement in the first 7 days of life. Patients who had already received analgesics or sedatives were excluded. NSAID use for patent ductus arteriosus was allowed. The study was conducted according to European Good Clinical Practice regulations and registered in the Dutch Trial Registry (trial No. 2290); Ethics Review Board approval (MEC-2009-250) and written informed consent from parents/legal guardians was obtained.

The Ethics Review Board initially did not allow the sucrose control group in the randomized controlled trial. Instead, after finishing including patients for this trial, and with approval of the Erasmus MC Ethics Review Board (MEC-2014-386), we applied the same pain assessment instruments to a group of age-matched patients who were given oral sucrose before PICC placement. Analysis of the data of all patients (paracetamol and sucrose group) took place after finishing recruitment of patients for the sucrose group.

\section{Outcome}

Pain assessed with the validated Premature Infant Pain Profile (PIPP) score $[7,8]$ was the primary outcome. Baseline data were assessed at $t=0$ (15 min prior to procedure) and pain was assessed from the start of the skin-breaking procedure of the PICC placement until $30 \mathrm{~s}$. We used sterile transparent covers for proper judgment of the neonate. A PIPP score $<7$ reflects no/minimal pain and $\geq 7-12 \mathrm{mild} /$ moderate pain; scores $>12$ reflect severe pain [7]. Because the PIPP was recently revised (drops in heart rate added), we analyzed how inclusion of heart rate change would have affected PIPP assessment [9]. PIPP scores were assigned by trained members of the research team (interrater reliability linearly weighted Cohen's $\kappa>0.65$ ).

The COMFORTneo score [10] was the secondary outcome and applied by trained nurses (interrater reliability linearly weighted Cohen's $\kappa>0.65)$. A COMFORTneo score between 14 and 30 indicates "pain or distress" (sensitivity of 0.81 and specificity of 0.90 ) [10].

\section{Interventions}

The procedure was started directly after paracetamol infusion (in 15 min through a peripheral venous cannula) and performed by experienced neonatologists or nurse practitioners. No additional sucrose was given.

In the separate sucrose study group, $0.5 \mathrm{~mL}$ (if $<1,000 \mathrm{~g}$ ) or 1.0 $\mathrm{mL}(\geq 1,000 \mathrm{~g})$ of sucrose $24 \%$ (EPMC Pharma, Belgium) was administered in the buccal cavity together with the use of a pacifier 2 min before PICC placement.

A blood sample of $200 \mu \mathrm{L}$ was taken to determine peak plasma levels 15-20 min after infusion.

While the PICC was inserted, one of the researchers assigned the PIPP score after observation for $30 \mathrm{~s}$. In addition, the attending nurse assigned the COMFORTneo score during the intervention after observation for $2 \mathrm{~min}$. Subjects in the control group receiving sucrose were assessed in exactly the same way.

\section{Sample Size Calculation}

With 20 infants per treatment group, the power to detect differences in the mean PIPP scores of 1 point equals $83 \%$. This calculation is based on the reported SD of PIPP scores assigned for a skin-breaking procedure, i.e., 1.4 points [8]. Thus, the total sample size was 60 subjects for the 3 paracetamol conditions.

\section{Randomization}

Stratified randomization for the 3 paracetamol dose groups was performed for 2 gestational age groups (24-28 weeks and $28^{1 / 7}-32$ weeks) by using sequentially numbered, sealed, and opaque envelopes. The envelopes for the different age groups were kept apart (marked A and B, respectively, and both numbered from 1 to 30 ). A nurse (practitioner) not involved in the care of the included patient opened the envelope for the applicable age group that contained the allocated dose of paracetamol. For each new patient, the next subsequently numbered envelope was opened. Patients could be included only once.

Both the researchers and all nursing and medical staff taking care of the subjects were blinded to the administered dose of 


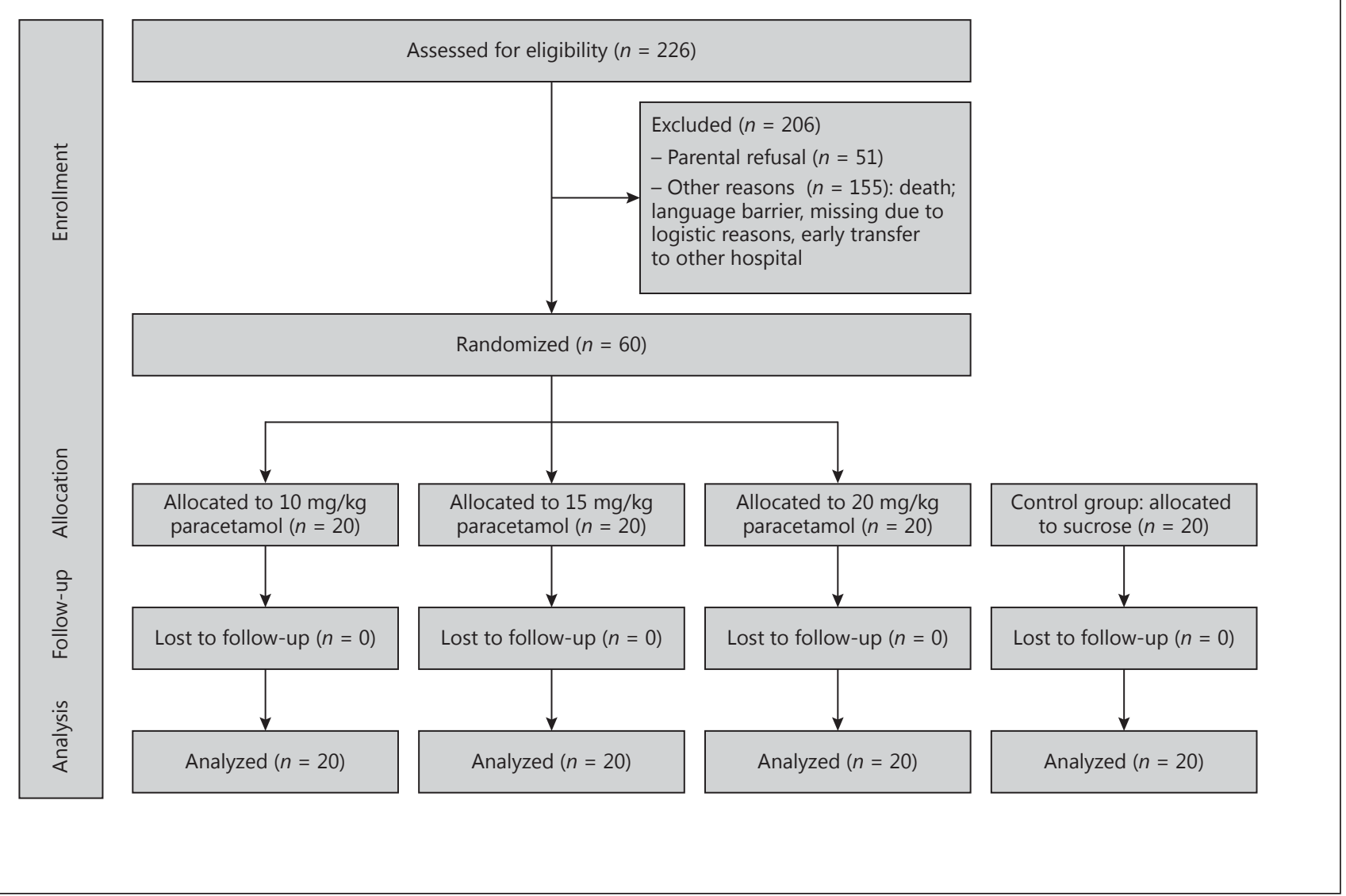

Fig. 1. Participant flowchart.

paracetamol. The medication was prepared by a nurse (practitioner) from another NICU unit. Unbinding of the study medication took place after all subjects were included.

\section{Statistical Analysis}

Background characteristics between the paracetamol groups and the sucrose group were compared using Fisher exact tests for categorical variables and Mann-Whitney $U$ tests for continuous variables.

Nonnormally distributed continuous variables were compared between the paracetamol groups using Kruskal-Wallis tests. Linear regression analysis with PIPP scores as the outcome variable was applied to determine the effects of the treatment (using 3 dummy variables for the 4 treatment conditions) as the predictor variable. In addition, administration of NSAIDs within $24 \mathrm{~h}$ before the procedure was added as a covariate. The distribution of the COMFORTneo and PIPP scores between the total paracetamol group and sucrose group were tested with Mann-Whitney U tests. Statistical significance was set at $p<0.05$ (2-sided). Data were analyzed using the intention-to-treat principle.

\section{Results}

In total, we assessed 266 patients for eligibility and randomized 60 patients to receive paracetamol (Fig. 1): 30 patients per gestational age group. All patients received the predetermined dose and all patients were included into the analyses. Background characteristics are shown in Table 1.

PIPP scores for the 3 different paracetamol groups were comparable: median $=8$ (IQR: 6-10.5), 7 (IQR: $6-9$ ), and 8 (IQR: $6-10)$ for the 10-, 15-, and $20-\mathrm{mg} / \mathrm{kg}$ paracetamol groups, respectively $(p=0.94)$. These scores reflect mild to moderate pain (Table 2; Fig. 2).

The COMFORTneo scores had a median of 12 (IQR: 10-14.8), 14 (IQR: 11-19.8), and 14 (IQR: 11-20) in the $10-, 15-$, and $20-\mathrm{mg} / \mathrm{kg}$ paracetamol groups, respectively $(p=0.35)$ (Table 2). Paracetamol plasma peak concentrations increased with paracetamol dose with median levels of $10.6 \mathrm{mg} / \mathrm{L}$ (IQR: 9.5-11.6), $16.5 \mathrm{mg} / \mathrm{L}$ (IQR: 14.9-19.6), 
Table 1. Background characteristics of the treatment groups

\begin{tabular}{|c|c|c|c|c|}
\hline \multirow[t]{2}{*}{ Characteristics } & \multicolumn{3}{|l|}{ Paracetamol } & \multirow{2}{*}{$\begin{array}{l}\text { Additional } \\
\text { control group } \\
\text { sucrose }(n=20)\end{array}$} \\
\hline & $\begin{array}{l}10 \mathrm{mg} / \mathrm{kg} \\
(n=20)\end{array}$ & $\begin{array}{l}15 \mathrm{mg} / \mathrm{kg} \\
(n=20)\end{array}$ & $\begin{array}{l}20 \mathrm{mg} / \mathrm{kg} \\
(n=20)\end{array}$ & \\
\hline Median gestational age (range), weeks & $27.8(24.0-31.1)$ & $27.9(24.2-30.4)$ & $28.8(24.2-30.3)$ & $27.9(24.1-31.4)$ \\
\hline Median birth weight (range), g & $970(462-1,550)$ & $988(475-1,440)$ & $885(630-1,380)$ & $898(520-1,330)$ \\
\hline SGA, $n(\%)$ & $4(20)$ & $5(25)$ & $7(35)$ & $8(40)$ \\
\hline \multicolumn{5}{|l|}{ Sex, $n(\%)$} \\
\hline Boy & $10(50)$ & $10(50)$ & $8(40)$ & $10(50)$ \\
\hline Girl & $10(50)$ & $10(50)$ & $12(60)$ & $10(50)$ \\
\hline Antenatal steroids, $n(\%)$ & $19(95)$ & $18(90)$ & $18(90)$ & $18(90)$ \\
\hline $\mathrm{PIH}, n(\%)$ & $4(20)$ & $7(35)$ & $3(15)$ & $5(25)$ \\
\hline PPROM, $n(\%)$ & $3(15)$ & $3(15)$ & $2(10)$ & $1(5)$ \\
\hline Median Apgar 1' (IQR) & $6(4.3-7.8)$ & $6(5.0-8.0)$ & $6(5.0-8.0)$ & $7.5(4.3-9.0)$ \\
\hline Median Apgar 5' (IQR) & $7.5(6.3-9.0)$ & $8(7.0-9.0)$ & $8(6.5-9.0)$ & $9(8.0-9.0)$ \\
\hline Median line placement PNA (IQR) & $4.5(2-6)$ & $6(5-6)$ & $6(1.3-7)$ & $3(1-7)$ \\
\hline
\end{tabular}

All background characteristics were comparable between the paracetamol groups and the sucrose group. SGA, small for gestational age; PIH, pregnancy-induced hypertension; PPROM, prolonged premature rupture of membranes; PNA, postnatal age.

Table 2. PIPP and COMFORTneo scores during PICC placement

\begin{tabular}{|c|c|c|c|c|c|c|}
\hline \multirow{2}{*}{$\begin{array}{l}\text { Pain assessment during } \\
\text { procedure }\end{array}$} & \multicolumn{3}{|l|}{ Paracetamol } & \multirow[t]{2}{*}{$p$ value $^{4}$} & \multirow{2}{*}{$\begin{array}{l}\text { Sucrose } 24 \% \\
(n=20)\end{array}$} & \multirow[t]{2}{*}{$p$ value } \\
\hline & $\begin{array}{l}10 \mathrm{mg} / \mathrm{kg} \\
(n=20)\end{array}$ & $\begin{array}{l}15 \mathrm{mg} / \mathrm{kg} \\
(n=20)\end{array}$ & $\begin{array}{l}20 \mathrm{mg} / \mathrm{kg} \\
(n=20)\end{array}$ & & & \\
\hline Median PIPP score (IQR) & $8(6-10.5)$ & $7(6-9)$ & $8(6-10)$ & 0.94 & $8(6.3-10)$ & 0.78 \\
\hline \multicolumn{7}{|l|}{ PIPP score ${ }^{1}, n(\%)$} \\
\hline$<7$ & $9(45)$ & $11(55)$ & $8(40)$ & & $9(45)$ & 0.46 \\
\hline $7-12$ & $10(50)$ & $8(40)$ & $10(50)$ & & $11(55)$ & \\
\hline$>12$ & $1(5)$ & $1(5)$ & $2(10)$ & & - & \\
\hline Median COMFORTneo score ${ }^{2}$ (IQR) & $12(10-14.8)$ & $14(11-19.8)$ & $14(11-20)$ & 0.35 & $11(10-13.8)$ & 0.08 \\
\hline COMFORTneo score $14-30^{3}, n(\%)$ & $6(30)$ & $10(50)$ & $10(50)$ & & $4(25)$ & 0.18 \\
\hline
\end{tabular}

PICC, peripherally inserted central catheter; PIPP, Premature Infant Pain Profile; ${ }^{1}$ PIPP $<7$ no to mild pain; $7-12$ moderate pain; $\geq 13$ severe pain. ${ }^{2}$ Three COMFORTneo scores were missing. ${ }^{3}$ A COMFORTneo score between 14 and 30 suggests pain and/or distress. ${ }^{4}$ Fisher exact and Kruskal-Wallis tests were applied as appropriate.

and $21.3 \mathrm{mg} / \mathrm{L}$ (IQR: 18.5-22.1), for the 10-, 15-, and 20$\mathrm{mg} / \mathrm{kg}$ paracetamol groups, respectively $(p<0.001)$. All subjects, except for 3 who received $10 \mathrm{mg} / \mathrm{kg}$ of paracetamol, had a peak plasma concentration $>9 \mathrm{mg} / \mathrm{L}$.

Additionally, 20 separate nonrandomized agematched control patients were included and received sucrose prior to PICC placement. Background characteristics were comparable (Table 1). Clinical outcome data are shown in Table 3. PIPP scores were not different compared to the paracetamol groups (median $=8$, IQR: $6.3-$
$10 ; p=0.78)$. Regression analysis showed that PIPP scores were comparable between the 4 treatment groups. NSAIDs added as a covariate did not significantly affect the PIPP scores $(p=0.60)$ either.

The median COMFORTneo scores of the sucrosetreated patients were available for 16 patients and had a median of 12 (IQR: 10-14.8), and were not statistically different compared to the total paracetamol-treated patients $(p=0.08)$. 
Fig. 2. PIPP scores during PICC placement

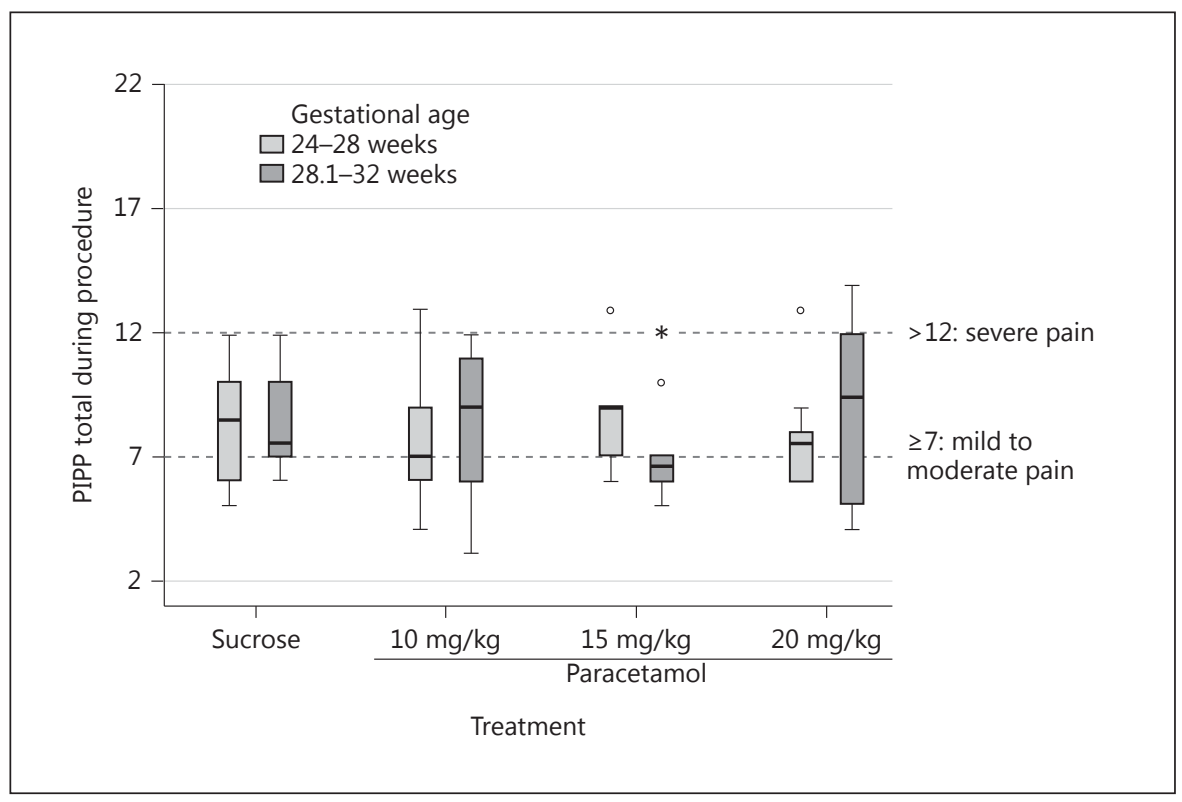
$(n=10$ in each box $)$.

Table 3. Clinical outcome data

\begin{tabular}{|c|c|c|c|c|}
\hline \multirow[t]{2}{*}{ Characteristics } & \multicolumn{3}{|c|}{ Paracetamol } & \multirow{2}{*}{$\begin{array}{l}\text { Additional control group } \\
\text { sucrose } 24 \% \\
(n=20)\end{array}$} \\
\hline & $\begin{array}{l}10 \mathrm{mg} / \mathrm{kg} \\
(n=20)\end{array}$ & $\begin{array}{l}15 \mathrm{mg} / \mathrm{kg} \\
(n=20)\end{array}$ & $\begin{array}{l}20 \mathrm{mg} / \mathrm{kg} \\
(n=20)\end{array}$ & \\
\hline RDS & $15(75)$ & $16(80)$ & $13(65)$ & $14(70)$ \\
\hline Mechanical ventilation & $15(75)$ & $16(80)$ & $14(70)$ & $13(65)$ \\
\hline Surfactant & $14(70)$ & $15(75)$ & $14(70)$ & $13(65)$ \\
\hline PDA & $8(40)$ & $7(35)$ & $12(60)$ & $8(40)$ \\
\hline Treatment indomethacin & $3(15)$ & $2(10)$ & $5(25)$ & 0 \\
\hline Treatment ibuprofen & $2(10)$ & $3(15)$ & $4(20)$ & $8(40)$ \\
\hline Surgery & $5(25)$ & $2(10)$ & $4(20)$ & $1(5)$ \\
\hline Sepsis & $9(45)$ & $9(45)$ & $10(50)$ & $12(60)$ \\
\hline NEC & $1(5)$ & $1(5)$ & $2(10)$ & $1(5)$ \\
\hline FIP & 0 & $2(10)$ & $2(10)$ & 0 \\
\hline Surgery NEC & 0 & $1(5)$ & $3(15)$ & $1(5)$ \\
\hline IVH & $2(10)$ & $5(25)$ & $6(30)$ & $4(20)$ \\
\hline Death & 0 & $4(20)$ & $2(10)$ & $2(10)$ \\
\hline
\end{tabular}

Values are presented as $n$ (\%). RDS, respiratory distress syndrome; PDA, patent ductus arteriosus; NEC, necrotizing enterocolitis; FIP, focal intestinal perforation; IVH, intraventricular hemorrhage.

Besides the PIPP, we also studied heart rate as included in the revised PIPP which takes both a rise and drop in heart rate into account as unwanted. Overall (3 paracetamol dose groups and a sucrose group), $20 \%$ of our patients showed a drop in heart rate (Fig. 3).

\section{Discussion}

Pain scores assigned to preterm infants during PICC placement after different paracetamol doses were comparable. Most patients showed mild to moderate pain. Comparison with a sucrose group suggested that paracetamol was not more effective but also noninferior to sucrose,

Roofthooft/Simons/van Lingen/Tibboel/ van den Anker/Reiss/van Dijk 


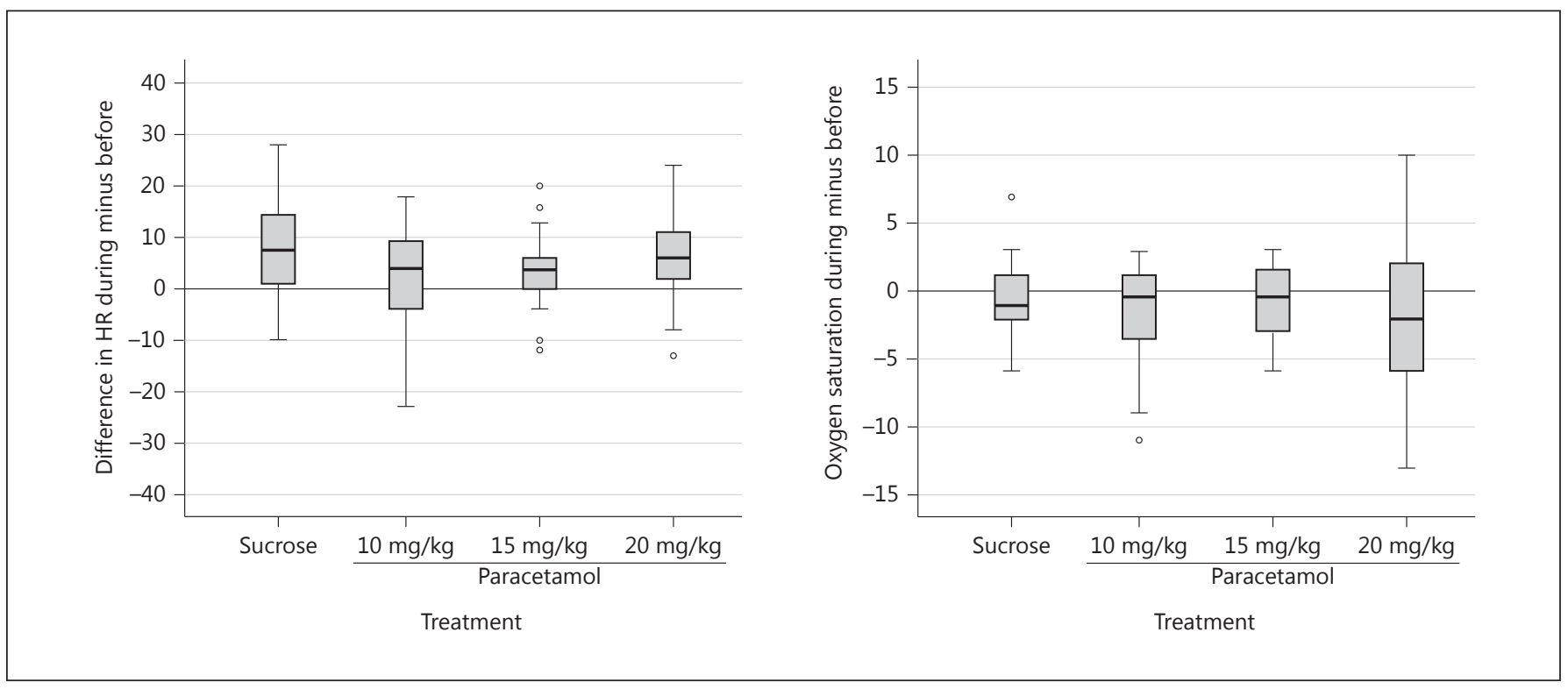

Fig. 3. Peri-intervention changes in heart rate (left panel) and oxygen saturation (right panel). HR, heart rate.

which makes paracetamol a drug of choice in those infants with a contraindication for sucrose. PICC placement has been rated painful ( 8 on a scale of $0-10$ ) by clinicians [11].

Comparative studies on efficacy of different paracetamol doses in preterm infants are lacking. While there are data from pharmacokinetics studies [12, 13], the pharmacodynamics of paracetamol in neonates are poorly described. Allegaert et al. [14] showed a reduction of pain after $20 \mathrm{mg} / \mathrm{kg}$ of paracetamol in preterm and term infants suffering from delivery trauma. Pharmacokinetics studies on intravenous paracetamol in preterm infants also suggest that a loading dose of $20 \mathrm{mg} / \mathrm{kg}$ intravenous paracetamol for neonates with postconceptional ages of $28-32$ weeks and body weights above $1.5 \mathrm{~kg}$ is sufficient for pain relief [15]. Pharmacokinetics/pharmacodynamics data in older infants suggest a target plasma concentration of $>9 \mathrm{mg} / \mathrm{L}$ [13]. Our study showed plasma concentrations $>9 \mathrm{mg} / \mathrm{L}$ in $95 \%$ of all subjects. As a consequence, the absence of pain relief by paracetamol in our study can probably not be explained by paracetamol doses that were too low. Our peak plasma concentrations even suggest that a $10-$ or $15-\mathrm{mg} / \mathrm{kg}$ loading dose might be sufficient.

The most obvious explanation of our findings is that paracetamol does not relieve pain associated with acute skin-breaking procedures [16]. The add-on value of paracetamol for acute procedural analgesia can be ques- tioned, as confirmed in previous studies on venous sampling and heel lancing [17]. A Cochrane review in 2015 showed no significant reduction in pain by paracetamol associated with heel lance or eye examinations [16], although Kabatas et al. [18] recently published results of reduced PIPP scores during ROP screening compared to placebo (12 [9-13] vs. 14 [13-15]; $p=0.01)$ after a single dose of paracetamol [19].

Thus, other analgesics need to be considered to improve analgesic therapy for PICC placement. A study with EMLA showed no pain relief compared to oral glucose $20 \%$ in preterm infants (gestational age: 28-37 weeks) [18], and tetracaine $4 \%$ gel was not beneficial in decreasing procedural pain associated with PICC placement in very small infants $[20,21]$. Table 4 shows an overview of PIPP scores for different analgesic treatments during skin-breaking procedures. A large variability between studies and within study groups can be seen. This suggests that there might be many more variables that contribute to pain expression.

Systemic administration of the short-acting opioid remifentanil might have more suitable analgesic qualities for acute procedural interventions in newborns [22]. PIPP scores during PICC placement were significantly lower $(\mathrm{p}<0.05)$ after remifentanil compared to sucrose $(6.1 \pm 1.4$ vs. $8.6 \pm 1.7)$ [23]. Shin et al. [25] showed a remifentanil dose-effect relationship with lower PIPP scores during PICC placement with high-dose $(0.25 \mu \mathrm{g} / \mathrm{kg})$ ver- 
Table 4. Overview of different analgesic treatment on PIPP scores for venipunctures

\begin{tabular}{|c|c|c|c|c|c|c|c|c|}
\hline & $\begin{array}{l}\mathrm{GA}, \\
\text { weeks }\end{array}$ & $\begin{array}{l}\text { Total, } \\
n\end{array}$ & $\begin{array}{l}\text { Placebo/ } \\
\text { no treatment }\end{array}$ & $\begin{array}{l}\text { Mean PIPP } \\
\pm \text { SD }\end{array}$ & $\begin{array}{l}\text { Pharmacological } \\
\text { treatment }\end{array}$ & $\begin{array}{l}\text { Mean PIPP } \\
\pm \text { SD }\end{array}$ & $\begin{array}{l}\text { Sugar solution/ } \\
\text { breastfeeding }\end{array}$ & $\begin{array}{l}\text { Mean PIPP } \\
\pm \text { SD }\end{array}$ \\
\hline \multicolumn{9}{|l|}{ Venipuncture } \\
\hline Carbajal [26] & $\geq 37$ & 180 & placebo & $11.3 \pm 3.17$ & & & $\begin{array}{l}\text { breastfeeding } \\
\text { glucose } 30 \%\end{array}$ & $\begin{array}{l}5.18 \pm 3.86 \\
4.38 \pm 3.82\end{array}$ \\
\hline Gradin [27] & $\geq 39$ & 120 & & & & & $\begin{array}{l}\text { breastfeeding } \\
\text { glucose } 30 \%\end{array}$ & $\begin{array}{c}10.37 \pm 2.46 \\
8.26 \pm 3.9\end{array}$ \\
\hline Ahn [28] & $25-41$ & 110 & no & $6.66 \pm 3.23$ & & & & \\
\hline Taddio [29] & $>36$ & 240 & sterile water & $8.9 \pm 3.97$ & & & sucrose $24 \%$ & $5.7 \pm 4.0$ \\
\hline Biran [30] & $25-36$ & 76 & & & sucrose $30 \%+$ EMLA & $7.2 \pm 3.2$ & sucrose $30 \%$ & $8.5 \pm 3.1$ \\
\hline Sahoo [31] & 37 & 160 & sterile water & $11.1 \pm 3.94$ & & & $\begin{array}{l}\text { dextrose } 25 \% \\
\text { expressed breast milk }\end{array}$ & $\begin{array}{l}5.22 \pm 3.33 \\
6.84 \pm 4.19\end{array}$ \\
\hline \multicolumn{9}{|l|}{ PICC placement } \\
\hline Lago [25] & $<32$ & 44 & placebo & 9 & remifentanil & 7 & & \\
\hline Shin [24] & $<32$ & 14 & & & $\begin{array}{l}\text { remifentanil } 0.1 \mu \mathrm{g} / \mathrm{kg} \\
\text { remifentanil } 0.25 \mu \mathrm{g} / \mathrm{kg}\end{array}$ & $\begin{array}{l}7.40 \pm 2.80 \\
4.86 \pm 0.83\end{array}$ & & \\
\hline $\begin{array}{l}\text { Roofthooft (current } \\
\text { study) }\end{array}$ & $24-32$ & 80 & & & $\begin{array}{l}\text { PCM } 10 \mathrm{mg} / \mathrm{kg} \\
\text { PCM } 15 \mathrm{mg} / \mathrm{kg} \\
\text { PCM } 20 \mathrm{mg} / \mathrm{kg}\end{array}$ & $\begin{array}{l}8.05 \pm 2.8 \\
7.87 \pm 2.13 \\
8.30 \pm 2.83\end{array}$ & Sucrose $24 \%$ & $8.15 \pm 2.16$ \\
\hline
\end{tabular}

PIPP, Premature Infant Pain Profile; GA, gestational age; PCM, paracetamol.

sus low-dose $(0.1 \mu \mathrm{g} / \mathrm{kg})$ remifentanil in 14 preterm infants. On the other hand, remifentanil use is related to adverse effects such as respiratory insufficiency and chest wall rigidity, making broader use or use outside an intensive care setting less feasible. Furthermore, skin-breaking procedures are performed multiple times per day, making remifentanil for all procedures less obvious.

Pain assessment in very preterm infants remains a challenge. Numerous pain assessment instruments are available, but only a few take gestational age into account, like the PIPP. The PIPP includes changes in heart rate and oxygen saturation, which might better reflect acute pain. Other than the originally published PIPP, the revised PIPP [9] takes both a rise and a drop in heart rate into account. The fact that $20 \%$ of our patients showed a drop in heart rate proves the usefulness of the revised PIPP score in future studies.

Several limitations of this study should be addressed. First, the study was not powered to determine a difference in either the COMFORTneo score or in proportions of infants with a PIPP score $>7$; to do so would require a much larger sample. Furthermore, the sucrose control group was added afterwards and used to compare pain scores with the randomized patients. The sucrose group was age-matched, but a selection bias cannot be ruled out. Second, the assessors of the sucrose group were not blinded to the administered therapy (sucrose), although they were not aware of the assessed pain scores in the paracetamol-treated infants; theoretically, this could have attributed to a bias in assessed results. Third, we demonstrated in this study that paracetamol was not more effective than sucrose for PICC placement, but we did not look at the additional effect of paracetamol in combination with sucrose. Fourth, 7 patients received NSAIDs for PDA treatment, reflecting standard clinical care of very preterm neonates. These patients were not excluded, but the use of NSAIDs was added as a covariate in our analyses. No influence on pain scores was found. Fifth, to avoid infusion site discomfort, the paracetamol was administered over $15 \mathrm{~min}$. The PICC placement was started directly after paracetamol infusion. It is not totally clear if paracetamol in these preterm infants has a direct effect at peak plasma levels, or if there is a certain, unknown delay. In our study, the time period may not have been long enough to reach optimal analgesia. Still, the peak plasma levels seemed to be adequate when compared to studies in older infants. Finally, we were not able to study safety in our study. The trial was underpowered to conclude anything about safety of paracetamol in very preterm newborns. Liver and kidney function were not routinely screened before and after administration of paracetamol of all patients.
Roofthooft/Simons/van Lingen/Tibboel/ van den Anker/Reiss/van Dijk 


\section{Conclusion}

In our quest for efficient pain medication before acute painful procedures in preterm infants, we studied the use of intravenous paracetamol. We did not show a benefit of paracetamol doses higher than $10 \mathrm{mg} / \mathrm{kg}$ for pain relief during PICC placement. Besides, paracetamol seemed to not be more effective than sucrose. In view of our findings, it is quite likely that paracetamol should not be the drug of choice for this or other skin-breaking procedures in preterm infants; whether it could be suitable for mild or more prolonged pain needs to be further elucidated.

\section{Acknowledgments}

We thank A.A. Bos and L.J.M. Groot Jebbink-Akkerman for participating in recruitment and data collection of patients and J. Hagoort for his help in preparing this manuscript. The clinical research activities of Sinno H.P. Simons were supported by a Clinical Fellowship of the Netherlands Organization for Health Research and Innovation (ZonMW 90713494).

\section{Disclosure Statement}

This study did not receive any research or project support. None of the authors has any financial relationship to disclose or a conflict of interest to declare. Clinical Trial Registry: the Dutch Trial Registry (Trial No. 2290).

\section{References}

1 Carbajal R, Rousset A, Danan C, Coquery S, Nolent P, Ducrocq S, Saizou C, Lapillonne A, Granier M, Durand P, Lenclen R, Coursol A, Hubert P, de Saint Blanquat L, Boelle PY, Annequin D, Cimerman P, Anand KJ, Breart G: Epidemiology and treatment of painful procedures in neonates in intensive care units. JAMA 2008;300:60-70.

2 Roofthooft DW, Simons SH, Anand KJ, Tibboel D, van Dijk M: Eight years later, are we still hurting newborn infants? Neonatology 2014;105:218-226

3 Brummelte S, Grunau RE, Chau V, Poskitt KJ, Brant R, Vinall J, Gover A, Synnes AR, Miller SP: Procedural pain and brain development in premature newborns. Ann Neurol 2012;71: 385-396.

4 Slater R, Cornelissen L, Fabrizi L, Patten D, Yoxen J, Worley A, Boyd S, Meek J, Fitzgerald $\mathrm{M}$ : Oral sucrose as an analgesic drug for procedural pain in newborn infants: a randomised controlled trial. Lancet 2010;376: 1225-1232.

5 Lasky RE, van Drongelen W: Is sucrose an effective analgesic for newborn babies? Lancet 2010;376:1201-1203

6 Carbajal R, Lenclen R, Jugie M, Paupe A, Barton BA, Annand KJ: Morphine does not provide adequate analgesia for acute procedural pain among preterm neonates. Pediatrics 2005;115:1494-1500.

7 Duhrsen L, Simons SH, Dzietko M, Genz K, Bendix I, Boos V, Sifringer M, Tibboel D, Felderhoff-Mueser U: Effects of repetitive exposure to pain and morphine treatment on the neonatal rat brain. Neonatology 2013;103: $35-43$.

8 Stevens B, Johnston C, Petryshen P, Taddio A: Premature Infant Pain Profile: development and initial validation. Clin J Pain 1996;12:1322.

Paracetamol for PICC Placement
22
9 Ballantyne M, Stevens B, McAllister M, Dionne K, Jack A: Validation of the premature infant pain profile in the clinical setting. Clin J Pain 1999;15:297-303.

10 Stevens BJ, Gibbins S, Yamada J, Dionne K, Lee G, Johnston C, Taddio A: The Premature Infant Pain Profile-Revised (PIPP-R): initial validation and feasibility. Clin J Pain 2014;30: 238-243.

11 van Dijk M, Roofthooft DW, Anand KJ, Guldemond F, de Graaf J, Simons S, de Jager Y, van Goudoever JB, Tibboel D: Taking up the challenge of measuring prolonged pain in (premature) neonates: the COMFORTneo scale seems promising. Clin J Pain 2009;25: 607-616.

12 Schultz S, DeSilva M, Gu TT, Qiang M, Whang K: Effects of the analgesic acetaminophen (paracetamol) and its para-aminophenol metabolite on viability of mouse-cultured cortical neurons. Basic Clin Pharmacol Toxicol 2012;110:141-144.

13 Wang C, Allegaert K, Tibboel D, Danhof M, van der Marel CD, Mathot RA, Knibbe CA: Population pharmacokinetics of paracetamol across the human age-range from (pre)term neonates, infants, children to adults. J Clin Pharmacol 2014;54:619-629.

14 Allegaert K, Naulaers G, Vanhaesebrouck S, Anderson BJ: The paracetamol concentration-effect relation in neonates. Paediatr Anaesth 2013;23:45-50.

15 Anderson BJ, Allegaert K: Intravenous neonatal paracetamol dosing: the magic of 10 days. Paediatr Anaesth 2009;19:289-295.

16 Ohlsson A, Shah PS: Paracetamol (acetaminophen) for prevention or treatment of pain in newborns. Cochrane Database Syst Rev 2015; 6:CD011219.
17 Simons SH, van Dijk M, Anand KS, Roofthooft D, van Lingen RA, Tibboel D: Do we still hurt newborn babies? A prospective study of procedural pain and analgesia in neonates. Arch Pediatr Adolesc Med 2003;157: 1058-1064.

18 Kabatas EU, Dursun A, Beken S, Dilli D, Zenciroglu A, Okumus N: Efficacy of single dose oral paracetamol in reducing pain during examination for retinopathy of prematurity: a blinded randomized controlled trial. Indian J Pediatr 2016;83:22-26.

19 Shah V, Taddio A, Ohlsson A: Randomised controlled trial of paracetamol for heel prick pain in neonates. Arch Dis Child Fetal Neonatal Ed 1998;79:F209-F211.

20 Marcatto J de O, Vasconcelos PC, Araujo CM, Tavares EC, Pereira e Silva Y: MLA versus glucose for PICC insertion: a randomised triple-masked controlled study. Arch Dis Child Fetal Neonatal Ed 2011; 96:F467-F468.

21 Lemyre B, Sherlock R, Hogan D, Gaboury I, Blanchard C, Moher D: How effective is tetracaine $4 \%$ gel, before a peripherally inserted central catheter, in reducing procedural pain in infants: a randomized double-blind placebo controlled trial (ISRCTN75884221). BMC Med 2006;4:11.

22 Ballantyne M, McNair C, Ung E, Gibbins S, Stevens B: A randomized controlled trial evaluating the efficacy of tetracaine gel for pain relief from peripherally inserted central catheters in infants. Adv Neonatal Care 2003;3: 297-307.

23 Allegaert K, Thewissen L, van den Anker JN. Remifentanil in neonates: a promising compound in search of its indications? Pediatr Neonatol 2012:53:387-388.
Neonatology 2017;112:150-158 DOI: $10.1159 / 000468975$ 
24 Shin SH, Kim HS, Lee J, Choi KY, Lee JH, Kim EK, Park MS, Choi JH: A comparative study of two remifentanil doses for procedural pain in ventilated preterm infants: a randomized, controlled study*. Pediatr Crit Care Med 2014;15:451-455.

25 Lago P, Tiozzo C, Boccuzzo G, Allegro A, Zacchello F: Remifentanil for percutaneous intravenous central catheter placement in preterm infant: a randomized controlled trial. Paediatr Anaesth 2008;18:736-744.

26 Carbajal R, Veerapen S, Couderc S, Jugie M, Ville Y: Analgesic effect of breast feeding in term neonates: randomised controlled trial. BMJ 2003;326:13.
27 Gradin M, Finnström O, Schollin J: Feeding and oral glucose-additive effects on pain reduction in newborns. Early Hum Dev 2004; 77:57-65.

28 Ahn Y, Jun Y: Measurement of pain-like response to various NICU stimulants for highrisk infants. Early Hum Dev 2007;83:255-262.

29 Taddio A, Shah V, Hancock R, Smith RW, Stephens D, Atenafu E, Beyene J, Koren G, Stevens B, Katz J: Effectiveness of sucrose analgesia in newborns undergoing painful medical procedures. CMAJ 2008;179:37-43. DOI: 10.1503/cmaj.071734.

30 Biran V, Gourrier E, Cimerman P, WalterNicolet E, Mitanchez D, Carbajal R: Analgesic effects of EMLA cream and oral sucrose during venipuncture in preterm infants. Pediatrics 2011;128:e63-e70. DOI: 10.1542/peds. 2010-1287.

31 Sahoo JP, Rao S, Nesargi S, Ranjit T, Ashok C, Bhat S: Expressed breast milk vs 25\% dextrose in procedural pain in neonates, a double blind randomized controlled trial. Indian Pediatr 2013;50:203-207.

32 Lemyre B, Hogan DL, Gaboury I, Sherlock R, Blanchard C, Moher D: How effective is tetracaine $4 \%$ gel, before a venipuncture, in reducing procedural pain in infants: a randomized double-blind placebo controlled trial. BMC Pediatr 2007;7:7. 